\title{
Standardisation of quality and reliability tests in the auto-parts industry: a structured approach concerning thermal systems
}

\author{
Fiorenzo Franceschini* and Domenico Maisano \\ Department of Management and Production Engineering (DIGEP), Politecnico di Torino, Corso \\ Duca degli Abruzzi 24, 10129 Torino, Italy
}

\begin{abstract}
In the automotive industry, first-tier suppliers play an important role, as they often establish long-term partnerships with multiple car-makers for developing and supplying complete car modules. One of the conditions underlying these partnerships is the quality and reliability of car modules. To achieve it, car-makers generally require multiple tests, often on $100 \%$ of the parts subcontracted. The number of tests required can be very high, even for modules with a relatively low level of customisation. Also, the configuration of the tests can vary significantly from one car-maker to another, even for the same test typologies. The aim of this paper is to present a decision-support tool for the standardisation of quality and reliability tests, which uses some already available information on previous tests (e.g. about their effectiveness, cost and simplicity of execution) and involves experts both from the supplier's and car-makers' staff. Test standardisation is guided by a simple procedure based on two steps: (i) grouping the tests required by different carmakers into typologies of homologous tests, with a similar protection level in terms of product and quality reliability, and (ii) determining the most appropriate configuration for each test typology. The description of the methodology is based on a real case-study concerning a worldwide supplier of thermal systems.
\end{abstract}

Keywords: quality and reliability test; auto-parts; first-tier supplier; car module; standardisation; test effectiveness; thermal systems

\section{Introduction and problem definition}

Outsourcing has been playing a strategic role in the automotive industry for many decades (Franceschini, Galetto, Pignatelli, \& Varetto, 2003). Most car-makers tend to build longterm partnership alliances with a relatively limited number of first-tier suppliers who are gaining increasing responsibility in the development of entire car modules (e.g. engines, transmissions, braking systems, seats, tyres, etc.) and their integration in the final product (Aláez-Aller \& Longás-García, 2010).

This tendency, accelerated by the recent socio-economic crisis, pushed suppliers into joining forces through mergers, acquisitions and joint ventures, so as to establish highly specialised and efficient organisations serving a large number of car-makers (Schaede, 2010; Tsu-Ming, Fan-Yun, \& Kai-I, 2013).

For simplifying the design and manufacturing stage without compromising product customiation, auto-parts suppliers generally develop a relatively small number of multifunctional modules/platforms (Minhas, Lehmann, \& Berger 2011). From the perspective of car-makers, ordering a complete module reduces the number of parts to be outsourced and thus the time of assembly, quality control cost, labour and administrative cost.

\footnotetext{
${ }^{*}$ Corresponding author. Email: fiorenzo.franceschini@polito.it
} 
In after-sales service, car-makers generally collect the so-called Voice of the Customer (Franceschini, 2002; Mavridou, Kehagias, Tzovaras, \& Hassapis, 2013; Sireli, Kauffmann, \& Ozan, 2007), to have an indication of the customer satisfaction with the full 'package' (i.e. the final product plus additional services, such as maintenance programme, roadside assistance, etc.). This information is strategic for car-makers oriented at developing new products or improving the existing ones according to the real customer requirements (van Driel \& Dolfsma, 2009). Sharing this information with suppliers, at least those of the most 'strategic' modules, is an important issue for consolidating partnerships. From the perspective of suppliers, this constant flow of information is essential to guide the quality improvement of the parts subcontracted, in accordance with the philosophy of 'continuous improvement' (Delbridge \& Barton, 2002).

Another condition necessary to reinforce the partnership between suppliers and carmakers is the quality and reliability of modules, which can have a very strong impact on the customer's quality perception of the final product. For example, a survey of an Italian car-maker showed that the majority of customer complaints relating to city-cars concerned the performance of the heating-ventilating-and-air-conditioning (HVAC) unit (Bassotto et al., 2005). For achieving reliability, car-makers generally require several tests, which should be carried out by suppliers, often on $100 \%$ of the parts supplied (Zhiqiang, Yuejun, \& Xiaole, 2013).

This paper focuses on a case-study concerning quality and reliability tests on thermal systems (e.g. electric compressors, HVAC units, radiators, etc.) produced by an important worldwide supplier, with a plant based in Northern Italy. For reasons of confidentiality, the company is kept anonymous and hereafter denominated with the acronym DTS. DTS supplies a large number of car-makers, such as Fiat, General Motors, PSA, Renault, Volkswagen, etc., and, by tradition, gives great importance to the product reliability.

It is worth noting that a scarcely debated issue in the scientific literature is that of the great variety of tests required by car-makers from their suppliers. This variability is twofold:

(1) In terms of test typologies. The total number of test typologies (i.e. groups of tests aimed at testing the same function/attribute) can be very high, especially for parts subject to prolonged and continuous use. In addition, similar tests can be considered as important by some car-makers and neglected by others.

(2) In terms of test configurations. For tests of the same typology, parameters (e.g. number of cycles, temperature, pressure, etc.) can vary significantly from one car-maker an other. The practical implication is that tests of the same typology may be more or less effective, expensive or simple to execute, depending on the configuration requested by car-makers.

The variety of test typologies and configurations can be large even for parts, such as thermal systems, with a relatively low level of customisation. This apparent paradox is explained by the fact that car-makers generally develop their test practices individually. This generates a certain 'affection' for the practices in use and a consequent reluctance towards the introduction of possible changes (Pil \& MacDuffie, 1999). Several existing techniques and procedures can be used for assessing the capability of suppliers to (i) perform the tests imposed by a car-maker and (ii) manufacture parts that satisfy these tests as much as possible; one of the most popular is the Production Part Approval Process (PPAP), developed by the Automotive Industry Action Group (AIAG) as part of the Advanced Product Quality Planning (APQP) manual (AIAG, 2006; Franceschini, 
Galetto, Maisano, \& Mastrogiacomo, 2011). On the other hand, suppliers can hardly play an active role in reducing test variety because of the lack of unified standards defining tests univocally and thoroughly. As a result, managing quality and reliability tests may be complicated for multiple reasons:

- Need for different types of test beds, some of which are dedicated to just a few tests.

- Flexibility of the operators, who must be able to switch from one configuration to one other (on single or multiple test beds) without making mistakes.

- Risk of biased conclusions about the actual reliability of the parts investigated, due to the fact that different test configurations can be more or less effective; for example, a part passing the test conducted by one car-maker could not pass that by another one.

- Operating costs likely to grow.

The previous considerations highlight the need for reducing the variety of tests in a rational way. The objective of this paper is the introduction of a simple standardisation procedure based on two main steps: (i) grouping the tests required by different carmakers into typologies of homologous tests, with a similar protection level in terms of product reliability, and (ii) determining the most reasonable and appropriate configuration for each test typology.

The proposed procedure uses the results of previous tests and the opinion of experts i.e. engineers and/or technicians - both from the supplier's and the car-makers' staff.

The remainder of this paper is organised in two sections. Section 2 illustrates in detail the standardisation procedure, providing an application example to reliability testing on radiators produced by DTS. The concluding section summarises the original contribution of the manuscript and discusses the advantages and limitations of the proposed procedure.

\section{Methodology}

Table 1 summarises the phases of the proposed procedure, which are described individually in the following subsections. The description is based on a case-study concerning tests on radiators supplied by DTS to four worldwide car-makers $\left(\mathrm{CM}_{1}-\mathrm{CM}_{4}\right)$. For reasons of confidentiality, car-makers are kept anonymous.

\subsection{Identification of test typologies}

One of the most delicate phases of the procedure is the classification of the tests imposed by various car-makers into groups of homologous tests. Consistently with the definition of reliability, i.e. 'the ability of a system or component to maintain its functions/attributes under stated conditions for a specified period of time' (O'Connor, 2002), homologous tests should be focused at testing the maintenance of similar functions/attributes (e.g. corrosion resistance, sealing, etc.). Unfortunately, this classification is complicated by the fact that there is no standard to define the set of functions/attributes of a generic system uniquely. We take the liberty of clarifying this issue through a similarity between the concept of measurement and that of reliability test.

A measurement is an operation for estimating an attribute of a real entity (e.g. the length of an object), using an appropriate instrument (e.g. a tape, a calliper, a laser interferometer or an echo sounder). Results of measurements obtained by different instruments can be compared since they are linked to the same reference unit (e.g. in the case of length 
Table 1. Typical phases of the test standardisation procedure, specifying input/output data and subjects involved.

\begin{tabular}{|c|c|c|c|}
\hline Phase denomination & Input & Output & Subjects involved \\
\hline $\begin{array}{l}\text { 2.1. Identification of test } \\
\text { typologies }\end{array}$ & $\begin{array}{l}\text { Technical } \\
\text { specifications } \\
\text { concerning the tests } \\
\text { required by the car- } \\
\text { makers }\end{array}$ & $\begin{array}{l}\text { List of the test } \\
\text { typologies, with their } \\
\text { individual } \\
\text { configurations }\end{array}$ & $\begin{array}{l}\text { A team of experts } \\
\text { on reliability } \\
\text { tests from DTS } \\
\text { staff }\end{array}$ \\
\hline $\begin{array}{l}\text { 2.2. Determination of } \\
\text { the importance level } \\
\text { of test typologies }\end{array}$ & $\begin{array}{l}\text { Questionnaires } \\
\text { submitted to experts }\end{array}$ & $\begin{array}{l}\text { Judgements defined on a } \\
\text { 5-level ordinal scale }\end{array}$ & $\begin{array}{l}\text { Experts on } \\
\text { reliability tests } \\
\text { both from the } \\
\text { staff of DTS and } \\
\text { that of each car- } \\
\text { maker }\end{array}$ \\
\hline $\begin{array}{l}\text { 2.3. Comparison of the } \\
\text { alternative } \\
\text { configurations (for } \\
\text { each individual test } \\
\text { typology) }\end{array}$ & - & - & - \\
\hline $\begin{array}{l}\text { 2.3.1. Definition of } \\
\text { judgements relating } \\
\text { to each configuration }\end{array}$ & $\begin{array}{l}\text { Results of previous } \\
\text { reliability tests and } \\
\text { questionnaires } \\
\text { submitted to experts }\end{array}$ & $\begin{array}{l}\text { Judgements defined on } \\
\text { 5-level ordinal scales } \\
\text { (concerning } \\
\text { effectiveness, cost, } \\
\text { simplicity of } \\
\text { execution) }\end{array}$ & $\begin{array}{l}\text { A team of experts } \\
\text { on reliability } \\
\text { tests from DTS } \\
\text { staff }\end{array}$ \\
\hline $\begin{array}{l}\text { 2.3.2. Selection of the } \\
\text { most suitable } \\
\text { configuration }\end{array}$ & $\begin{array}{l}\text { Judgements resulting } \\
\text { from Phases 2.2.- } \\
\text { 2.3.1. }\end{array}$ & $\begin{array}{l}\text { Selection of a } \\
\text { configuration for each } \\
\text { test typology }\end{array}$ & $\begin{array}{l}\text { A team of experts } \\
\text { on reliability } \\
\text { tests from DTS } \\
\text { staff }\end{array}$ \\
\hline
\end{tabular}

measurements, the metre). This link originates from the instrument calibration process, which establishes a connection between the measurement result and the reference unit by an unbroken metrological traceability chain (JCM200:2012, 2012). Of course, the results of measurements performed using different instruments may differ in several aspects, such as accuracy, cost, simplicity of execution, etc.

On the other hand, reliability tests can be viewed as special measurements for assessing the ability of a component to maintain a certain function/attribute over time. Even considering the same function/attribute, there can be different instruments (test beds) and procedures (configurations of test parameters) to test it, as evidenced by the variety of tests suggested by different car-makers. Unfortunately, the results of tests performed with different instruments and/or procedures are not easy to compare for at least two reasons: (i) the difficulty in identifying the functions/attributes of a system uniquely, and (ii) the lack of standard references for establishing the conditions under which to evaluate the maintenance of these functions/attributes.

The large variety of tests imposed by various car-makers is also reflected by their denominations: in most cases, car-makers use acronyms or reference numbers referred to internal procedures.

A possible way to overcome these limitations (at least partially), allowing comparisons among tests suggested by different car-makers, is to create typologies of homologous tests. This activity can be carried out by a team of experts, consisting of engineers and/or technicians with a deep experience and knowledge of the tests of interest. 
Tests of the same typology will differ in several aspects, such as effectiveness defined as the ability of the test to reveal the maintenance of a certain function/attribute, in a realistic operational context - cost, simplicity of execution, etc. We are aware that the definition of test typologies is a subjective operation. However, the fact that it is carried out by a team of multiple experts represents a partial guarantee for obtaining reasonable results.

Table 2 lists the test typologies defined by the team of experts from DTS staff. It can be seen that test typologies are variegated; about half of them are required by the majority of car-makers but only 9 of 28 are shared by all of them. Also, there are several tests required by few or even individual car-makers. Those requested by unique car-makers (highlighted in grey in Table 2) were not taken into account.

\subsection{Determination of the importance level of test typologies}

The level of importance of a test typology depends on the negative effects, which may originate from the loss of the function/attribute investigated. This judgement may change from one car-maker to an other. For example, test typology ' $\mathrm{T}_{11}-$ Leak' is regarded

Table 2. List of the test typologies concerning radiators manufactured by DTS, sorted alphabetically by their denomination.

\begin{tabular}{|c|c|c|c|c|c|}
\hline Ref. no. & Test typology denomination & $\mathrm{CM}_{1}$ & $\mathrm{CM}_{2}$ & $\mathrm{CM}_{3}$ & $\mathrm{CM}_{4}$ \\
\hline $\mathrm{T}_{1}$ & Bursting test & $x$ & $x$ & $\sqrt{ }$ & $\boldsymbol{V}$ \\
\hline $\mathrm{T}_{2}$ & Drain packing & $x$ & $\checkmark$ & $x$ & $x$ \\
\hline $\mathrm{T}_{3}$ & Draincock & $\sqrt{ }$ & $\sqrt{ }$ & $\checkmark$ & $x$ \\
\hline $\mathrm{T}_{4}$ & External corrosion (salt spray) & $\checkmark$ & $\checkmark$ & $\checkmark$ & $\checkmark$ \\
\hline $\mathrm{T}_{5}$ & External corrosion (severe wastewater analysis) & $\boldsymbol{V}$ & $\boldsymbol{V}$ & $\checkmark$ & $\boldsymbol{V}$ \\
\hline $\mathrm{T}_{6}$ & Fluid cooler heat exchange & $x$ & $\checkmark$ & $x$ & $x$ \\
\hline $\mathrm{T}_{7}$ & Functional characteristics & $x$ & $x$ & $\checkmark$ & $x$ \\
\hline $\mathrm{T}_{8}$ & General characteristics & $x$ & $x$ & $\checkmark$ & $x$ \\
\hline $\mathrm{T}_{9}$ & Internal cleanliness & $\sqrt{ }$ & $\sqrt{ }$ & $\checkmark$ & $\sqrt{ }$ \\
\hline $\mathrm{T}_{10}$ & Internal corrosion & $\checkmark$ & $\checkmark$ & $\checkmark$ & $\sqrt{ }$ \\
\hline $\mathrm{T}_{11}$ & Leak & $\sqrt{ }$ & $\boldsymbol{V}$ & $\checkmark$ & $\sqrt{ }$ \\
\hline $\mathrm{T}_{12}$ & Long life coolant resistance & $x$ & $\checkmark$ & $x$ & $x$ \\
\hline $\mathrm{T}_{13}$ & Low temperature & $\checkmark$ & $\checkmark$ & $\boldsymbol{V}$ & $x$ \\
\hline $\mathrm{T}_{14}$ & Performance measurement & $\boldsymbol{V}$ & $\boldsymbol{V}$ & $\boldsymbol{V}$ & $\sqrt{ }$ \\
\hline $\mathrm{T}_{15}$ & Phys./Chem./ Environm./Mech. & $x$ & $x$ & $\checkmark$ & $\checkmark$ \\
\hline $\mathrm{T}_{16}$ & Pollution & $x$ & $x$ & $x$ & $\sqrt{ }$ \\
\hline $\mathrm{T}_{17}$ & Pressure cap wear & $\checkmark$ & $x$ & $x$ & $x$ \\
\hline $\mathrm{T}_{18}$ & Pressure cycle durability & $\boldsymbol{V}$ & $\sqrt{ }$ & $\sqrt{ }$ & $\sqrt{ }$ \\
\hline $\mathrm{T}_{19}$ & Pressure resistance & $x$ & $\sqrt{ }$ & $x$ & $x$ \\
\hline $\mathrm{T}_{20}$ & Resistance to fastening dowels & $x$ & $\checkmark$ & $x$ & $x$ \\
\hline $\mathrm{T}_{21}$ & Resistance to fluid attack & $x$ & $x$ & $x$ & $\checkmark$ \\
\hline $\mathrm{T}_{22}$ & Resistance to gravelling & $x$ & $x$ & $x$ & $\sqrt{ }$ \\
\hline $\mathrm{T}_{23}$ & Resistance to painting & $x$ & $x$ & $\sqrt{ }$ & $\checkmark$ \\
\hline $\mathrm{T}_{24}$ & Rubber seal & $x$ & $\checkmark$ & $x$ & $x$ \\
\hline $\mathrm{T}_{25}$ & Temperature endurance & $x$ & $x$ & $\checkmark$ & $x$ \\
\hline $\mathrm{T}_{26}$ & Thermal cycle durability & $\checkmark$ & $\sqrt{ }$ & $\checkmark$ & $\checkmark$ \\
\hline $\mathrm{T}_{27}$ & Vacuum & $\checkmark$ & $x$ & $x$ & $\checkmark$ \\
\hline $\mathrm{T}_{28}$ & Vibration durability & $\checkmark$ & $\checkmark$ & $\sqrt{ }$ & $\checkmark$ \\
\hline
\end{tabular}

Note: Test typologies required and non-required by each of the car-makers $\left(\mathrm{CM}_{1}-\mathrm{CM}_{4}\right)$ are respectively marked by the symbols ' $\boldsymbol{V}$ ' and ' $\boldsymbol{X}$ '. The test typologies highlighted in grey are required by unique car-makers and therefore will not be taken into account in the rest of the analysis. 
Table 3. Definition of the 5-level scales used for evaluating (i) the importance of a test typology and (ii) the effectiveness, cost and simplicity of execution of the relevant test configurations.

\begin{tabular}{|c|c|c|c|c|}
\hline Level & $\begin{array}{l}\text { Importance (of a test } \\
\text { typology) }\end{array}$ & $\begin{array}{l}\text { Effectiveness (of a } \\
\text { configuration) }\end{array}$ & $\begin{array}{c}\text { Cost (of a } \\
\text { configuration) }\end{array}$ & $\begin{array}{l}\text { Simplicity (of a } \\
\text { configuration) }\end{array}$ \\
\hline 1 & Not at all important & Not at all effective & Very high cost & Not at all simple \\
\hline 2 & Low importance & Low effectiveness & High cost & Low simplicity \\
\hline 3 & Medium importance & Medium effectiveness & Medium cost & Medium simplicity \\
\hline 4 & High importance & High effectiveness & Low cost & High simplicity \\
\hline 5 & $\begin{array}{l}\text { Very high } \\
\text { importance }\end{array}$ & $\begin{array}{l}\text { Very high } \\
\text { effectiveness }\end{array}$ & Very low cost & Very high simplicity \\
\hline N/A & Not applicable & Not applicable & Not applicable & Not applicable \\
\hline
\end{tabular}

as very important by the totality of the car-makers, because leakage from the radiator can rapidly lead to compromising its main function of cooling the car engine. Instead, some car-makers consider the typology ' $\mathrm{T}_{10}$-Internal corrosion' as important, while others do not.

This judgement was collected by questionnaires submitted to experts in reliability tests, both from the DTS' and car-makers' staff. Experts from the car-makers were engineers and/or technicians dealing with DTS for technical issues about the tests of interest. Judgments were collected for DTS and each of the four car-makers separately.

To make judgments as simple as possible, a 5-level ordinal scale was adopted (see the second column in Table 3). The category N/A (not applicable) was assigned to car-makers not requiring the test typology of interest.

In order to facilitate the formulation of judgments, we provided respondents with the results of a previous Failure Mode, Effects, and Criticality Analysis - FMECA (Bouti \& Kadi, 1994) on the radiator, which identified and prioritised the main failures.

It is reasonable to assume that the major test typologies are those investigating the maintenance of functions/attributes potentially affected by the most critical failures. Table 4 illustrates the results of the questionnaires for each test typology. The most important typologies at the global level are those requested by a large number of car-makers and those with relatively high importance judgements.

For each test typology, it is possible to determine the median ${ }^{1}$ level of importance:

$$
\tilde{I}=\operatorname{median}\left(I_{i}\right)
$$

$I_{i}$ being the importance levels assigned by experts from DTS and each of the car-makers (if applicable). Precisely, subscript $i \in\{$ DTS $\} \cup A$, where $A \subseteq\left\{\mathrm{CM}_{1}, \mathrm{CM}_{2}, \mathrm{CM}_{3}, \mathrm{CM}_{4}\right\}$ indicates groups of experts from the subset of car-makers requiring the test typology of interest. E.g. the test typology $\mathrm{T}_{1}$ is required by $\mathrm{CM}_{3}$ and $\mathrm{CM}_{4}$, but not by $\mathrm{CM}_{1}$ and $\mathrm{CM}_{2}$, therefore $A=\left\{\mathrm{CM}_{3}, \mathrm{CM}_{4}\right\}$.

$\tilde{I}$ is used in the next stages of the procedure (see the last column of Table 4). For simplicity, it was assumed that judgements by the groups of experts from DTS and each of the car-makers have the same relevance.

It can be noticed that, even for tests of the same typology, there can be significant differences between the judgements by different respondents. This is probably the result of their specific experience on previous tests. 
Table 4. Judgements of experts from DTS and four car-makers $\left(\mathrm{CM}_{1}-\mathrm{CM}_{4}\right)$ on the importance of the test typologies in Table 2.

\begin{tabular}{lllllll}
\hline & \multicolumn{7}{c}{$I$} \\
\cline { 2 - 6 } Test ref. no. & DTS & $\mathrm{CM}_{1}$ & $\mathrm{CM}_{2}$ & $\mathrm{CM}_{3}$ & $\mathrm{CM}_{4}$ & $\tilde{I}$ \\
\hline $\mathrm{T}_{1}$ & 4 & $\mathrm{~N} / \mathrm{A}$ & $\mathrm{N} / \mathrm{A}$ & 5 & 4 & 4 \\
$\mathrm{~T}_{3}$ & 1 & 1 & 2 & 1 & $\mathrm{~N} / \mathrm{A}$ & 1 \\
$\mathrm{~T}_{4}$ & 3 & 5 & 3 & 4 & 4 & 4 \\
$\mathrm{~T}_{5}$ & 3 & 4 & 4 & 5 & 5 & 4 \\
$\mathrm{~T}_{9}$ & 2 & 1 & 1 & 3 & 1 & 1 \\
$\mathrm{~T}_{10}$ & 1 & 4 & 3 & 1 & 1 & 1 \\
$\mathrm{~T}_{11}$ & 4 & 4 & 5 & 5 & 5 & 5 \\
$\mathrm{~T}_{13}$ & 3 & 2 & 1 & 2 & N/A & 2 \\
$\mathrm{~T}_{14}$ & 5 & 5 & 5 & 3 & 2 & 5 \\
$\mathrm{~T}_{15}$ & 1 & $\mathrm{~N} / \mathrm{A}$ & $\mathrm{N} / \mathrm{A}$ & 1 & 1 & 1 \\
$\mathrm{~T}_{18}$ & 5 & 5 & 5 & 4 & 4 & 5 \\
$\mathrm{~T}_{23}$ & 3 & N/A & N/A & 2 & 4 & 3 \\
$\mathrm{~T}_{26}$ & 5 & 4 & 5 & 5 & 5 & 5 \\
$\mathrm{~T}_{27}$ & 4 & 5 & N/A & N/A & 3 & 4 \\
$\mathrm{~T}_{28}$ & 3 & 5 & 5 & 5 & 2 & 5 \\
\hline
\end{tabular}

Note: $\tilde{I}$ is the median, the importance values relating to each test typology.

\subsection{Comparison of the alternative configurations}

\subsubsection{Definition of judgments relating to each configuration}

In this phase, attention is focussed on the configurations imposed by different car-makers for each of the test typologies selected in Section 2.1. For the purpose of example, Table 5 reports the configurations concerning the test typologies ' $\mathrm{T}_{1}-$ Bursting test' and ' $\mathrm{T}_{26}-$ Thermal cycle durability'.

For each of these configurations, different aspects were investigated. The first is the test's level of effectiveness in detecting possible abnormalities of the part in maintaining its functions/attributes. The survey was carried out by submitting questionnaires to a team of DTS experts, already involved in the activities described in Sections 2.1. and 2.2.

Again, judgements were defined on a 5-level ordinal scale (see the third column in Table 3). In general, it was assumed that the most effective tests tend to be severe/conservative, generating a significant amount of 'false positives', i.e. parts that did not pass the test, while being functionally acceptable (in statistical terms, a greater type-I error). Therefore, very high levels of effectiveness are justified only for test typologies of high importance, for which it can be reasonable to minimise the probability of 'false negatives' (in statistical terms, the type-II error), i.e. parts with deteriorated function(s)/attribute(s), which passed the test. Table 6 shows the resulting judgements (see the column 'Eff', for each car-maker).

Respondents were subsequently asked to judge the level of cost and simplicity of execution of each configuration. Cost, which generally depends on test time and hourly cost of equipment/operator(s), is quite simple to estimate. On the other hand, simplicity which may depend on the complexity of test set-up, risk of human error, operators' degree of familiarity with the equipment, etc. - is more difficult to quantify. These judgements were defined on two 5-level scales (see the fourth and fifth column in Table 3). The scale related to cost is 'reversed', so that low and high levels have a negative and positive connotation respectively. Table 6 shows the resulting judgements (see the columns 'Cost' and 'Simpl' for each car-maker). 
Table 5. Configurations of the test parameters for test typologies ' $\mathrm{T}_{1}-$ Bursting test' and ' $\mathrm{T}_{26}-$ Thermal cycle durability', from the perspective of four car-makers $\left(\mathrm{CM}_{1}-\mathrm{CM}_{4}\right)$.

\begin{tabular}{|c|c|c|c|c|}
\hline $\begin{array}{l}\text { Test } \\
\text { typ. }\end{array}$ & $\mathrm{CM}_{1}$ & $\mathrm{CM}_{2}$ & $\mathrm{CM}_{3}$ & $\mathrm{CM}_{4}$ \\
\hline \multirow[t]{2}{*}{$\mathrm{T}_{1}$} & N/A & N/A & $\begin{array}{l}\text { Fill radiator with test } \\
\text { fluid; increase } \\
\text { pressure at } 4 \text { bar/ } \\
\text { min, up to } 3.5 \text { bar; }\end{array}$ & $\begin{array}{l}\text { Pressure } \leq \\
\quad\left(1.5^{*} \text { inlet }\right. \\
\text { pressure); }\end{array}$ \\
\hline & & & $\begin{array}{l}\text { Hold this pressure } \\
\text { for } 30 \mathrm{~s}\end{array}$ & $\begin{array}{l}\text { Increase pressure at } \\
0.1 \mathrm{bar} / \mathrm{s} \text {, up to } \\
3.5 \mathrm{bar} \text {; } \\
\text { Hold this pressure } \\
\text { for } 300 \mathrm{~s} \text {; ambient } \\
\text { temperature: } 23 \\
\quad+5^{\circ} \mathrm{C} \text {. }\end{array}$ \\
\hline \multirow[t]{4}{*}{$\mathrm{T}_{26}$} & $\begin{array}{l}\text { No. of cycles: } \\
\quad 1000\end{array}$ & No. of cycles: 7000 & No. of cycles: 1000 & No. of cycles: 2500 ; \\
\hline & $\begin{array}{l}\text { Coolant } \\
\text { temperature: } \\
\text { from } 0^{\circ} \mathrm{C} \text { to } \\
100 \pm 2^{\circ} \mathrm{C}\end{array}$ & $\begin{array}{l}50 \% \text { water } 50 \% \text { coolant } \\
\text { as medium; }\end{array}$ & $\begin{array}{l}\text { Cycle rate: } 7 \text { cycles/ } \\
\text { h; }\end{array}$ & $\begin{array}{l}\text { Pre-conditioning: } \\
\quad 2 \mathrm{~h} \text { at } 20^{\circ} \mathrm{C}\end{array}$ \\
\hline & $\begin{array}{l}\text { Pressure: } 130 \pm \\
10 \mathrm{kPa} .\end{array}$ & $\begin{array}{l}\text { Coolant temperature: } \\
\text { from } 20^{\circ} \mathrm{C}(30 \mathrm{~s} \text { max. }) \\
\text { to } 90^{\circ} \mathrm{C}(2 \mathrm{~min}) \text { and to } \\
20^{\circ} \mathrm{C}(2 \mathrm{~min}) \text { with } \\
\text { flow rate } 40 \mathrm{l} / \mathrm{min}\end{array}$ & $\begin{array}{l}\text { Coolant temperature: } \\
\text { from }-30^{\circ} \mathrm{C} \text { to } \\
100^{\circ} \mathrm{C}\end{array}$ & $\begin{array}{l}\text { Ambient } \\
\text { temperature: } 23 \\
\quad \pm 5^{\circ} \mathrm{C}\end{array}$ \\
\hline & & & Pressure: 1.3 bar & $\begin{array}{l}\text { High temperature of } \\
\text { coolant: } 113^{\circ} \mathrm{C} ; \\
\text { Low temperature of } \\
\text { coolant: } 23^{\circ} \mathrm{C} ; \\
\text { Switch duration } \\
\text { between high and } \\
\text { low temperature } \\
\text { phase: } 5 \mathrm{~s} ;\end{array}$ \\
\hline
\end{tabular}

\subsubsection{Selection of the most suitable configuration}

Among the possible configurations, the 'best' is selected according to the procedure illustrated in the flowchart in Figure 1.

As shown, in the case there are two (or more) configurations that satisfy the condition

$$
\min \left(\operatorname{Eff}_{i} \mid \operatorname{Eff}_{i} \geq \tilde{I}\right)
$$

with $i \in A$, i.e. the subset of car-makers requiring the test typology of interest, the selection continues by applying a lexicographic order based on cost and simplicity of execution. In the unlikely event of a further tie, the final decision would be determined manually by the team of experts.

The last column in Table 5 reports the configurations selected applying the previous procedure.

For the purpose of example, as regards $\mathrm{T}_{9}$, two are the configurations satisfying Equation (2): $\mathrm{CM}_{2}$ and $\mathrm{CM}_{3}$. Since these two alternatives have the same cost level (i.e. 1), the 
Table 6. Judgments of experts from DTS about the degree of effectiveness (Eff), cost and simplicity of execution (Simpl) of the test configurations proposed by any of the car-makers $\left(\mathrm{CM}_{1}-\mathrm{CM}_{4}\right)$

\begin{tabular}{|c|c|c|c|c|c|c|c|c|c|c|c|c|c|c|}
\hline \multirow{2}{*}{$\begin{array}{l}\text { Test } \\
\text { Ref. no. }\end{array}$} & \multirow{2}{*}{$\tilde{I}$} & \multicolumn{3}{|c|}{$\mathrm{CM}_{1}$} & \multicolumn{3}{|c|}{$\mathrm{CM}_{2}$} & \multicolumn{3}{|c|}{$\mathrm{CM}_{3}$} & \multicolumn{3}{|c|}{$\mathrm{CM}_{4}$} & \multirow[b]{2}{*}{ Selected config } \\
\hline & & Eff & Cost & Simpl & Eff & Cost & Simpl & Eff & Cost & Simpl & Eff & Cost & Simpl & \\
\hline $\mathrm{T}_{1}$ & 4 & N/A & N/A & N/A & N/A & N/A & N/A & 3 & 2 & 2 & 5 & 3 & 2 & $\mathrm{CM}_{4}$ \\
\hline $\mathrm{T}_{3}$ & 1 & 3 & 1 & 3 & 2 & 2 & 2 & 1 & 3 & 3 & N/A & N/A & N/A & $\mathrm{CM}_{3}$ \\
\hline $\mathrm{T}_{4}$ & 4 & 3 & 2 & 2 & 4 & 4 & 2 & 5 & 4 & 2 & 5 & 2 & 2 & $\mathrm{CM}_{2}$ \\
\hline $\mathrm{T}_{5}$ & 4 & 4 & 1 & 2 & 5 & 2 & 1 & 5 & 1 & 2 & 4 & 1 & 1 & $\mathrm{CM}_{1}$ \\
\hline $\mathrm{T}_{9}$ & 1 & 3 & 2 & 1 & 1 & 1 & 3 & 1 & 1 & 1 & 3 & 3 & 1 & $\mathrm{CM}_{2}$ \\
\hline $\mathrm{T}_{10}$ & 1 & 4 & 5 & 5 & 2 & 5 & 5 & 1 & 3 & 4 & 2 & 5 & 5 & $\mathrm{CM}_{3}$ \\
\hline $\mathrm{T}_{11}$ & 5 & 3 & 4 & 3 & 5 & 4 & 4 & 5 & 5 & 5 & 4 & 3 & 3 & $\mathrm{CM}_{3}$ \\
\hline $\mathrm{T}_{13}$ & 2 & 1 & 2 & 1 & 1 & 1 & 1 & 1 & 1 & 2 & N/A & N/A & N/A & $\mathrm{CM}_{2}{ }^{\mathrm{a}}$ \\
\hline $\mathrm{T}_{14}$ & 5 & 4 & 4 & 2 & 2 & 3 & 2 & 3 & 2 & 4 & 3 & 2 & 4 & $\mathrm{CM}_{1}{ }^{\mathrm{a}}$ \\
\hline $\mathrm{T}_{15}$ & 1 & N/A & N/A & N/A & N/A & N/A & N/A & 1 & 3 & 4 & 3 & 2 & 1 & $\mathrm{CM}_{3}$ \\
\hline $\mathrm{T}_{18}$ & 5 & 4 & 5 & 5 & 3 & 4 & 5 & 4 & 5 & 3 & 4 & 5 & 4 & $\mathrm{CM}_{1}^{\mathrm{a}}$ \\
\hline $\mathrm{T}_{23}$ & 3 & N/A & N/A & N/A & N/A & N/A & N/A & 5 & 2 & 3 & 4 & 1 & 1 & $\mathrm{CM}_{4}$ \\
\hline $\mathrm{T}_{26}$ & 5 & 3 & 3 & 4 & 5 & 4 & 5 & 4 & 4 & 3 & 5 & 3 & 5 & $\mathrm{CM}_{2}$ \\
\hline $\mathrm{T}_{27}$ & 4 & 2 & 1 & 1 & N/A & N/A & N/A & N/A & N/A & N/A & 5 & 1 & 1 & $\mathrm{CM}_{4}$ \\
\hline $\mathrm{T}_{28}$ & 5 & 4 & 1 & 1 & 4 & 1 & 2 & 4 & 2 & 2 & 3 & 1 & 1 & $\mathrm{CM}_{3}{ }^{\mathrm{a}}$ \\
\hline
\end{tabular}

Note: The last column shows the configuration selected according to the procedure described in Section 2.3.2.

${ }^{a}$ In this case, $\operatorname{Eff}_{i}<\tilde{I}$ for all the alternative configurations; as a result, Equation (2) cannot be applied. The selected configuration is the one with max(Eff $)_{i}$ 


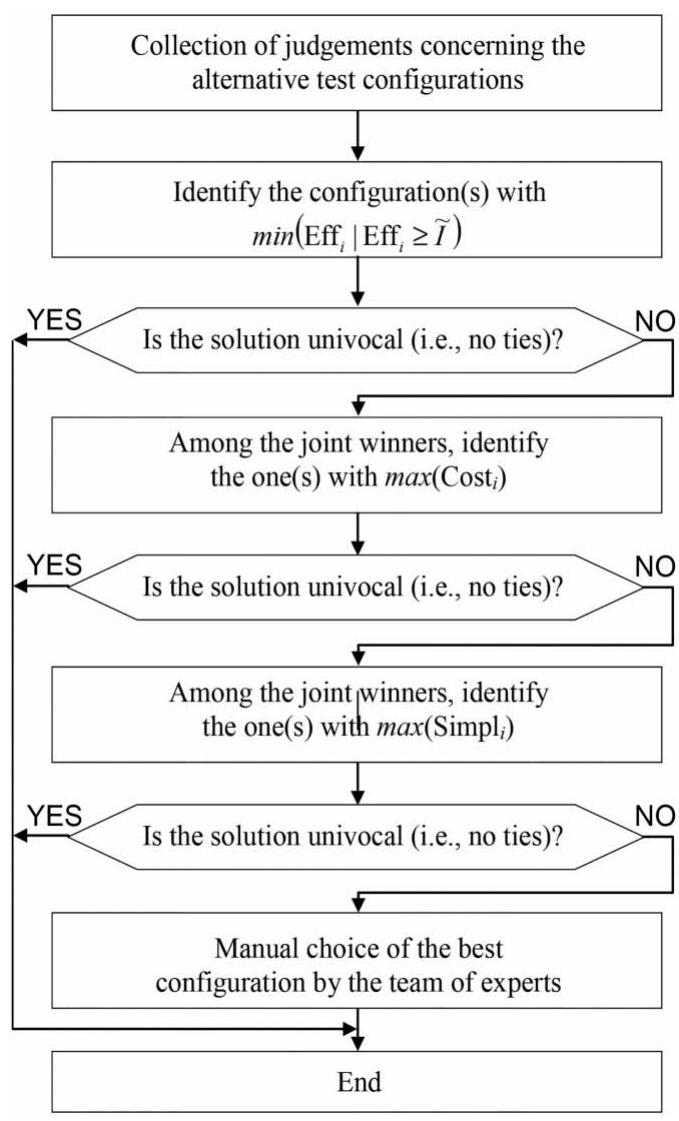

Figure 1. Flowchart depicting the procedure for selecting the 'best' configuration, for a certain test typology.

selection is determined by simplicity of execution, which is higher for $\mathrm{CM}_{2}$ (i.e. 3) with respect to $\mathrm{CM}_{3}$ (i.e. 1).

The logic of selection seen above is based on several assumptions:

- The best configuration is not defined 'from scratch', instead it is selected among those imposed by the car-makers. Defining the parameters of a test is actually a very delicate operation because of the multiplicity of factors (e.g. as regards radiator: number of cycles, temperature, pressure, composition of coolant, etc.), which may affect its effectiveness. These factors and their possible interactions should be examined rigorously by experimental plans (Box, Hunter, \& Hunter, 1978). It was assumed that the test configurations were defined by the car-makers following this approach.

- It was assumed that test effectiveness and severity, i.e. the probability of generating 'false positives', go hand in hand. The fact that the selected configuration should have a level of effectiveness as close as possible to that of $\tilde{I}$ prevents selection of (i) tests that are too severe with respect to their relatively low importance, or (ii) tests that are not very effective, despite their relatively high importance. The authors are aware that, in some cases, this assumption may not be realistic. For example, there could exist very effective configurations with relatively low 
incidence of 'false positives'. When, on the basis of its experience, the team of expert feels that this hypothesis should be relaxed, one could select the configuration satisfying the condition:

$$
\max \left(\operatorname{Eff}_{i}\right)
$$

Also, Equation (3) could be used when there is no configuration satisfying Equation (2), because Eff $\mathrm{i}_{\mathrm{i}}<\tilde{I} \forall i \in A$ (see tests $\mathrm{T}_{13}, \mathrm{~T}_{14}, \mathrm{~T}_{18}$ and $\mathrm{T}_{28}$ in Table 6).

- Among the three types of judgements (effectiveness, cost and simplicity) related to the configurations, it was implicitly assumed the ordering Eff $>$ Cost $>$ Simpl (symbol ' $>$ ' means 'preferred to'). However, the technique based on lexicographic ordering could be replaced by more complex techniques, such as multi-criteria decision-making methods (Franceschini, Galetto, \& Maisano, 2007; Köksalan, Wallenius, \& Zionts, 2011).

\section{Final remarks}

This work focused on the problem of the standardisation of reliability tests for auto-parts suppliers. This problem originates from (at least) two reasons: (i) in general there are no unified standards defining exhaustive and univocal sets of tests, and (ii) any car-maker requires a set of tests, with ad hoc configurations deriving from their specific experience and work practices.

The proposed procedure is a first attempt to address this problem in a simple and economic way. A more elegant and sophisticated approach would be that of designing new optimal configurations, in terms of effectiveness, through rigorous design of experiments. Unfortunately, the price to pay would be too high because of the large number of experiments required. On the contrary, the proposed technique exploits a large amount of information already available (i.e. results of previous tests) and the expertise of engineers and/ or technicians of suppliers and car-makers.

The procedure was applied in DTS on a number of thermal systems, such as radiator, HVAC, heater core, etc., focussing on the test configurations imposed by several worldwide car-makers. The example presented in this paper illustrated the philosophy behind the procedure.

Thanks to its simplicity and low cost, the procedure was judged by DTS staff as very useful and easy to implement. For this reason, it will be extended to other components manufactured by the company. The proposed methodology can be considered as a decision-support tool for rationalising the management of reliability tests for auto-parts suppliers, which is complementary to other procedures, such as the AIAG's APQP/ PPAP (AIAG, 2006).

The proposed approach has some limitations, summarised as follows:

- Test standardisation is internal with respect to a specific supplier, since it depends on the degree of expertise of engineers/technicians, the information regarding previous tests, the available equipment (test beds) and the variety of tests imposed by car-makers. As a consequence, the application of the procedure to different suppliers could lead to different results, even considering homologous parts.

- Several phases of the procedure are subjective, such as the interpretation of the results of previous tests or the formulation of judgments. To avoid disputes, these 
phases should be carried out in a transparent manner, involving technical staff with a certain expertise on reliability tests, both from suppliers and car-makers.

- The procedure can be applied to auto-parts with a relatively low degree of customisation, where comparing tests related to similar product models is not rushed.

- Standardised tests may be rejected by some car-makers, who are 'attached' to their configurations. However, the results of the proposed procedure may be used for persuading the most reluctant car-makers to accept standardised tests, as they will probably be more effective, cheaper and simpler than others.

\section{Acknowledgements}

Authors gratefully acknowledge the contribution of Giridharan Sundar and the company staff of DTS, in developing the proposed methodology.

\section{Note}

1. Using the average value as a central tendency indicator may be inappropriate since $I_{i}$ values are defined on an ordinal scale (Stevens 1946).

\section{References}

Aláez-Aller, R., \& Longás-García, J.C. (2010). Dynamic supplier management in the automotive industry. International Journal of Operations and Production Management, 30(3), 312-335.

Automotive Industry Action Group. (2006). Production part approval process (4th ed.). (PPAP-4). Cincinnati, OH: Author.

Bassotto, C., Daprile, F., Davanzo, G., Franceschini, F., Maisano, D., \& Spirito, F. (2005). Customer Satisfaction: spunti per l'analisi in automatico di reclami o di lamentele su prodotti/servizi. Qualità, XXXV(1-2), 35-38.

Bouti, A., \& Kadi, D.A. (1994). A state-of-the-art review of FMEA/FMECA. International Journal of Reliability, Quality and Safety Engineering, 1(4), 515-543.

Box, G.E.P., Hunter, W.G., \& Hunter, J.S. (1978). Statistics for experimenters. New York: Wiley.

Delbridge, R., \& Barton, H. (2002). Organizing for continuous improvement: Structures and roles in automotive components plants. International Journal of Operations and Production Management, 22(6), 680-692.

van Driel, H., \& Dolfsma, W. (2009). Path dependence, initial conditions, and routines in organizations: The Toyota production system re-examined. Journal of Organizational Change Management, 22(1), 49-72.

Franceschini, F. (2002). Advanced quality function deployment. Boca Raton, FL: St. Lucie Press/ CRC Press LLC.

Franceschini, F., Galetto, M., \& Maisano, D. (2007). Management by measurement: Designing key indicators and performance measurement systems. Berlin: Springer.

Franceschini, F., Galetto, M., Maisano, D., \& Mastrogiacomo, L. (2011). ISO/TS 16949: Analysis of the diffusion and current trends. Proceedings of the Institution of Mechanical Engineers, Part B, Journal of Engineering Manufacture, 225(5), 735-745.

Franceschini, F., Galetto, M., Pignatelli, A., \& Varetto, M. (2003). Outsourcing: Guidelines for a structured approach. Benchmarking, 10(3), 246-260.

JCM200:2012. (2012). International Vocabulary of Metrology (VIM) - Basic and General Concepts and Associated Terms.

Köksalan, M., Wallenius, J., \& Zionts, S. (2011). Multiple criteria decision making: From early history to the 21st century. Singapore: World Scientific.

Mavridou, E., Kehagias, D., Tzovaras, D., \& Hassapis, G. (2013). Mining affective needs of automotive industry customers for building a mass-customization recommender system. Journal of Intelligent Manufacturing, 24, 251-265.

Minhas, S.U.H., Lehmann, C., \& Berger, U. (2011). Concept and development of intelligent production control to enable versatile production in the automotive factories of the future. 
Glocalized solutions for sustainability in manufacturing. Proceedings of the 18th CIRP International Conference on Life Cycle Engineering, Technische Universität Braunschweig, Braunschweig, Germany, May 2nd-4th, 57-62.

O'Connor, P.D.T. (2002). Practical reliability engineering (4th ed.). New York: Wiley.

Pil, F.K., \& MacDuffie, J.P. (1999). What makes transplants thrive: Managing the transfer of "best practice" at Japanese auto plants in North America. Journal of World Business, 34(4), 372391.

Schaede, U. (2010). Globalisation and the reorganisation of Japan's auto parts industry. International Journal of Automotive Technology and Management, 10(2-3), 270-288.

Sireli, Y., Kauffmann, P., \& Ozan, E. (2007). Integration of Kano's model into QFD for multiple product design. IEEE Transactions on Engineering Management, 54(2), 380-390.

Stevens, S.S. (1946). On the theory of scales of measurement. Science, 103(2684), 677-680.

Tsu-Ming, Y., Fan-Yun, P., \& Kai-I, H. (2013). The critical factors for implementing the quality system of ISO/TS 16949 in automobile parts industry in Taiwan. Total Quality Management \& Business Excellence, 24(3-4), 355-373.

Zhiqiang, L., Yuejun, Z., \& Xiaole, H. (2013). Integrating run-based preventive maintenance into the capacitated lot sizing problem with reliability constraint. International Journal of Production Research, 51(5), 1379-1391. 